\title{
Ariassos ve Kremna'da Gözlemlenen Su Sistemleri ve Sarnıçlar Hakkında Bir Değerlendirme
}

\author{
An Assessment of the Water Systems and Cisterns in Ariassos and Kremna
}

\begin{abstract}
Mehmet KÜRKÇÜ *
Öz: Bu makalede Pisidia Bölgesi'nin güneybatısındaki kentler içerisinde bulunan farklı mimari özelliklere sahip sarnıçlar ele alınmaktadır. Böylelikle günümüze değin gerçekleştirilen arkeolojik kazılar ve yüzey araştırmaları sürecinde gereken ilgiyi görmemiş olan bu mütevazi su yapısı hakkında gelecekte oluşturulacak bir envanter ya da corpus çalışmasına katkıda bulunulacağı düşünülmektedir. Çalışma içerisinde Ariassos ve Kremna kentlerinden örneklerle sarnıçların coğrafi konumları, bulundukları yerin seçimi ve mimari özellikleri ele alınarak uygulanan ortak model ve teknikler irdelenip bu hidrolik strüktürlerin günlük yaşantıya sosyo-ekonomik ve kültürel açıdan katkıları değerlendirilmektir. Savaş ve çatışmaların yerini barış ve huzurun aldığı Pax Romana sonrasında Roma’nın belli bir kent ve yerleşim modelini imparatorluk sınırları içerisinde kalan tüm bölgelere dayatmasına bağlı olarak Pisidia Bölgesi'nde de şehircilik ve kentsel düzenlemelerin hızla yayıldığı görülür. Kentlerdeki tüm gelişmelere, hidrolik düzenlemelere rağmen Ariassos ve Kremna'da sınırlı kapasitelere sahip ev tipi sarnıçların halkın günlük su ihtiyacını karşılamaya kesintisiz olarak devam ettikleri görülmektedir.
\end{abstract}

Anahtar sözcükler: Ariassos, Kremna, Su Sistemleri, Sarnıç, Pisidia

Abstract: In this contribution the cisterns in the South-Western cities of the Pisidian Region with their various features are examined. In this manner, the intention is to make a contribution towards the inventory or corpus of examples of cisterns, a small water structure which has often been neglected in archaeological excavations and in survey work conducted to date. In this article the geographical positions of the cisterns, the reasons for the choice of their positions, together with their architectural features are examined through some examples from the cities of Ariassos and Cremna, the common models and the techniques employed are investigated and the contributions made by these hydraulic structures to daily life are interpreted in terms of their socio-economic and cultural contribution. It is observed that Rome imposed a certain settlement pattern upon whole regions within the borders of the empire during the pax Romana, in which war and conflicts were replaced by peace, and consequently, town planning and urban settlement patterns also spread rapidly in Pisidia. Despite all the developments and the hydraulic systems and arrangements in the cities, the domestic type of limited capacity cisterns in Ariassos and Cremna seem to have provided citizens with a continuous supply of fresh water.

Keywords: Ariassos, Kremna, Water Systems, Cistern, Pisidia

XVIII. yüzyılın başında P. Lucas tarafından tespit edilip ardından C. Lanckoronski ve ekibince detaylıca incelenen, günümüzde de farklı bilim dallarından uzmanların oluşturduğu bir ekiple yürütülen araştırma ve kazılarıyla yalnızca Anadolu'nun değil, aynı zamanda tüm arkeoloji dünyasının örnek kentleri arasında ilk sıralarda yer alan Sagalassos ile aynı bölgede bulunmala-

* Dr., Université de Sorbonne, Antalya. mhmtkurkcu@gmail.com 
rına rağmen (Fig. 1), bu kentler üzerine yapılan çalışmalar çok kısıtlı olup programlı, bilimsel arkeolojik kazıların sadece 1970-1972 yıllarında Kremna'da Prof. Dr. J. İnan tarafindan gerçekleştirildiği görülür.

Günümüze değin Pisidia Bölgesi'nin güneybatısında yürütülen çalışmalar genellikle epigrafi üzerine olup, bilhassa ilk dönemlerde bu yöreye gelen araştırmacılar daha çok yazıtlarla ilgilenmişlerdir.

1982 senesinde S. Mitchell öncülügünde Pisidia Antiokheia'sında başlayan araştırmalar zamanla bu makalenin içerisinde yer alan kentleri de kapsayan "The Pisidian Survey Project" isimli bir projeye dönüşmüş ve 1998-2012 yılları arasında sonradan (2006) Ankara İngiliz Arkeoloji Enstitüsü Müdürü olan Dr. L. Vandeput başkanlığında devam etmiştir. Proje kapsamında S. Mitchell söz konusu kentlerden Kremna'da 1985-1987 yılları arasında üç; Ariassos'ta 1988 ve 1990 yıllarında iki; Panemoteikhos’ta 1993 ve 1995 yıllarında iki ve Sia'da 1995 ve 1996 yıllarında iki dönem yüzey araştırmaları gerçekleştirmiştir. 1993 yılında geniş bir alana yayılan çalışmalar sürecine Melli de dahil olmuştur. Daha sonraları bu kentte Vandeput başkanlığında bir ekip 1998 yılından başlayarak 2000 yılı da dahil olmak üzere 3 dönem boyunca araştırmalarda bulunmuştur (Bu araştırmalarla ilgili raporlar 1983 yılından itibaren AST bildirilerinde düzenli olarak yayınlanmıştır).

Sınırları kesin olarak belirlenemese de yaklaşık olarak kuzeyden güneye $120 \mathrm{~km}$ ve doğudan batıya 170 km'lik bir alanı kaplayan Pisidia Bölgesi, Kilikia, Pamphylia, Karia ve Lykia örneklerinde görüldüğü üzere, Anadolu'nun güney ve batısında yer alan diğer yerleşim bölgeleri gibi denize kıyısı olmayıp daha dağlık bir coğrafyaya sahip olması vb. özelliklerine rağmen, arkeolojik buluntulara ve epigrafik belgelere göre, M.Ö. IV. yüzyıldan M.S. VI. yüzyıla uzanan süreçte sayıları 54'e ulaşan kent ve kent devletini barındırmıştır (Mitchell 1998, 238).

\section{Kentlerin Coğrafi Konumu}

\section{Ariassos}

Ariassos kenti Antalya ilinin $56 \mathrm{~km}$ kuzeybatısında ortalama 900 ile $1050 \mathrm{~m}$ yükseklikte kurulmuştur. Kenti 1882 yılında ziyaret eden Lanckoronski ve ekibi yanılgıya düşerek buranın Kretopolis olduğunu belirtmişlerdir (Lanckoronski 1893, 128). Yerleşimi doğrulukla tespit eden ve 1892 yılında Ariassos yazıtlarını yayınlayan V. Bérard'dır (Bérard 1892, 426-427).

Ariassos kenti kalıntılarının, dik bir vadinin yamaçlarında düzenlenen teraslar üzerinde toplandıkları görülür.

1988 yılında kentte ilk yüzey araştırması sonrasında tespit ettikleri mezar yazıtları ile bouleuterion ve prytaneon'un bulunduğu Hellenistik kent merkezini referans alan S. Mitchell \& M. Waelkens $(1989,66)$ şehrin kuruluşunu da bu döneme, yani M.Ö. 189/188 yıllarına tarihlendirmektedirler. Roma Dönemi'nde genişleyen kentte inşa edilen yapılar arasında, kentin $3 \mathrm{~km}$ güneyinde bulunan Akkoç köyünün yukarılarındaki bir kaynaktan aquaeductus ile getirilen suyla beslenen anıtsal çeşme (nymphaeum), gymnasium ve hamam yapısı yer alır (Mitchell 1990a, 124). Mitchell'a (1990b, 148) göre, hamam kompleksi için gereken ve aquaeductus ile temin edilen suları depolamaya yönelik iki adet sarnıç nymphaeum'un önünde uzanan meydanın batısında, zeminin altına yerleştirilmiştir.

Pisidia Survey Project sürecinde 1990 yılı Ariassos ikinci dönem yüzey araştırmalarını gerçekleştiren ekibin üyelerinden kentin hidrolik sistemleri ve özellikle kente su sağlayan aquaeductus üzerinde çalışan E. Owens (2006, 151-157), antikçağda kentte en az bir adet doğal su kaynağı olduğunu, Hellenistik kent merkezinin yaklaşık $70 \mathrm{~m}$ kuzeydoğusunda bulunan ve 
Roma Dönemi'ne tarihlediği üzeri tonoz çatı ile örtülü, duvarları hidrolik sıvayla kaplı, iki bölümden oluşan yapının da bu kaynaktan beslendiğini savlamaktadır. Günümüzde kent içinde ve yakın çevresinde aktif hiçbir kaynak bulunmadığını, Ariassosluların Roma Dönemi öncesinde politik ve askeri karışıklıklar nedeniyle tüm su ihtiyaçlarını sadece kent içindeki mevcut imkanlarla karşıladıklarını ilave eder. Bu olanaklar ve kaynaklar yine o dönemlerde "Grekoromen dünyada", hemen her evde bulunan çoğunlukla şişe tipli sarnıçlar ve dikdörtgen planlı, üstü taş bloklarla örtülü rezervuarlardan oluşmaktadır. Doğal kaynaktan elde edilen ve su depolama yapılarında toplanan sular yeterli miktarlarda olup, kentin Roma Dönemi'nde yapılan düzenlemeler öncesinde yaşamını sürdürmesine olanak sağlamıştır.

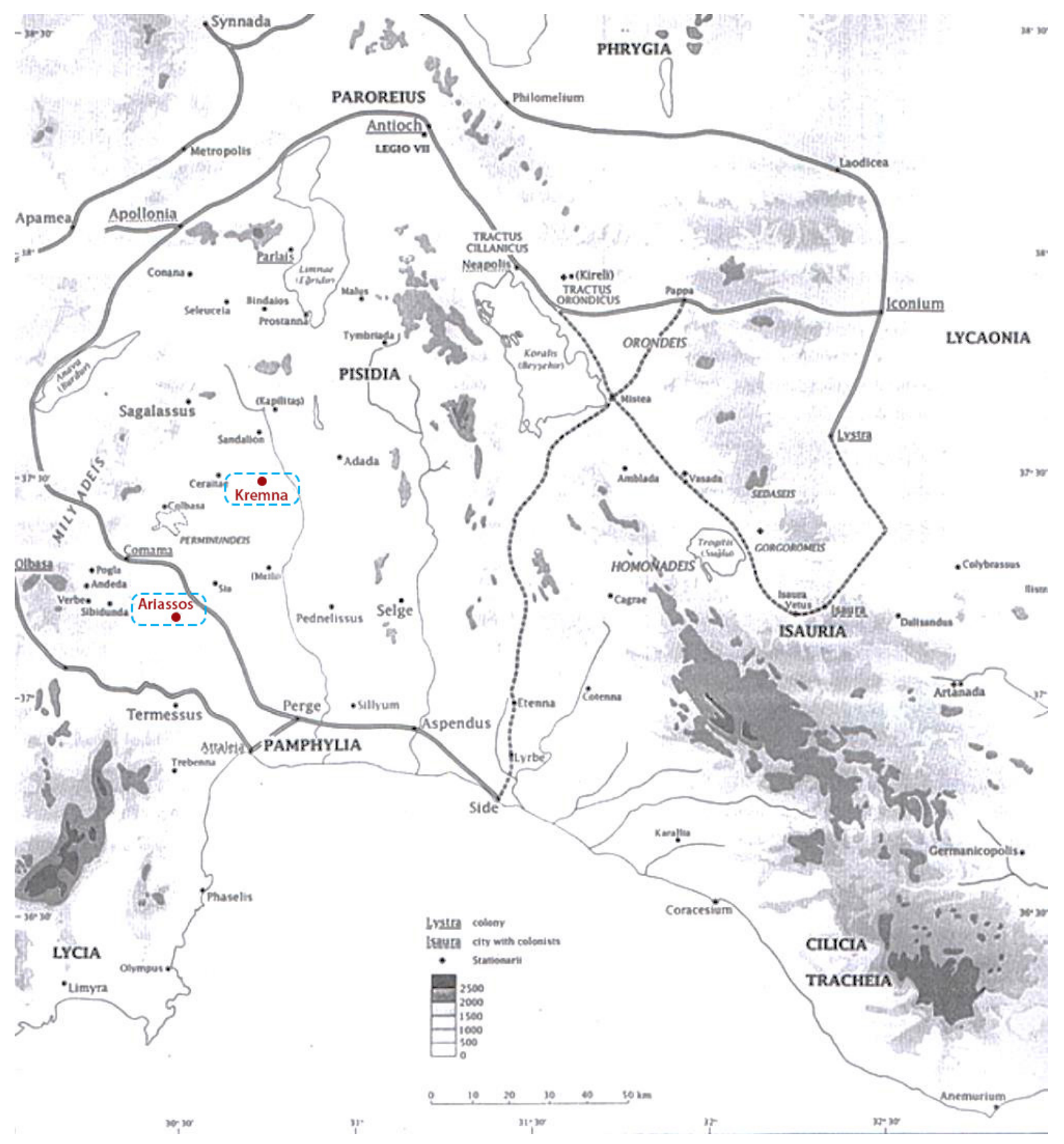

Fig. 1. Pisidia Bölgesi haritası, (www.pisidia.org) 
Owens, tiyatronun karşısındaki tepenin eteklerinde inşa edilen dört bölümlü büyük kapasiteli kamu sarnıcının herhangi bir kanal ya da boru ile doldurulduğuna dair bir bulgu olmadığını, muhtemelen yamaçtan akan veya tiyatrodan gelen sularla ya da her ikisiyle birden beslendiğini ve kalıntıların Roma Dönemi’ne ait olduğunu belirtir.

C. Dorl-Klingenschmid (2001, 174-176) ise Anadolu'daki çeşme yapılarını incelediği çalışmasında, kentten kuzeye giden yol üzerinde, yolun başlangıcından $1,5 \mathrm{~km}$ mesafede kayalardan çıkan kaynağın sularıyla beslenen bir çeşme yapısından ve kent içinde, güneydoğu yamacında yer alan, üzerinde su toplama yapılarının inşa edildiği ve içerisinde iki adet kemer görünen bir sarnıçtan bahsetmektedir.

Günümüzde her üç araştırmacının da bahsettiği söz konusu strüktür (Fig. 2) incelendiğinde üzeri, orta ölçekli moloz taşlar, agrega

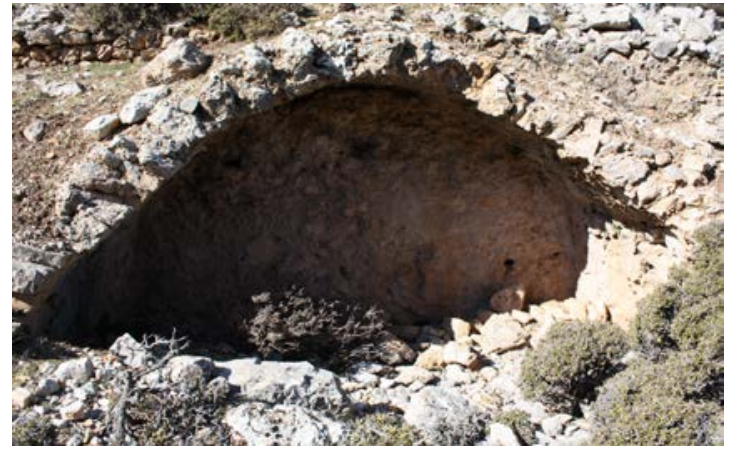

Fig. 2. Ariassos, Hidrolik Fonksiyonlart Olduğu Düşünülen Yapı ve bağlayıcı malzemeden oluşan beton tonozlu çatı ile örtülü, ortasında pencere ya da kapı gibi açıklık bırakılan bir duvarla iki bölüme ayrılmış bir yapı olduğu görülmektedir. Duvarlar moloz ve harç ile dikilmiş olsa da üzerlerinde içeride su tutmaya yönelik herhangi bir hidrolik sıva kalıntısı bulunmamaktadır. Bu nedenle en azından içerisinde neredeyse çatı başlangıcına kadar gelen moloz ve toprak yığını temizlenmedikçe bu yapının gerçek fonksiyonunu kesin bir şekilde belirlemek mümkün görünmemektedir.

\section{Sarnıçlar}

Ariassos’ta gözlemlenen, konumları ve kisıtlı kapasiteye sahip olmaları nedeniyle şahsi kullanıma yönelik inşa edildiği düşünülen dört adet diğer sarnıcın (Kürkçü 2014, 322-323) 3 farklı model içerisinde sınıflandırılması uygundur.

C 3 sarnic1 (Fig. 3) kentin bat1 ucunun kuzey yamacına inşa edilmiştir. $2,71 \mathrm{~m}$ uzunluğunda, 2,06 m eninde olup yüksekliği de kapak seviyesinden zemini kaplayan toprak ve moloz yığınına kadar 1,28 m'dir. Kenarları tamamen yuvarlandığından neredeyse silindi-

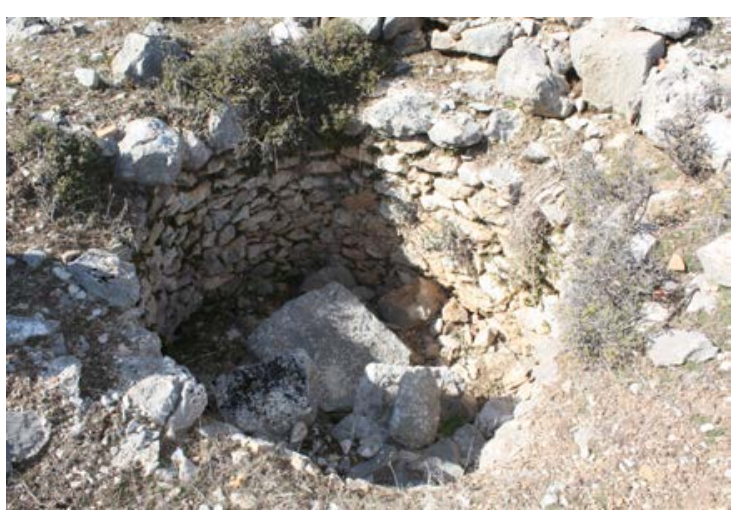

Fig. 3. Ariassos C 3 sarnıcl rik bir plana sahip olup diğer sarnıçlarda görülen, içerideki serin havayı muhafaza edip buharlaşmayı önlemenin yanı sıra örtme kolaylığı sağlayan, yukarıya doğru çıktıkça daralan ve "şişe formlu sarnıç" denmesine neden olan mimari düzenleme burada bulunmamaktadır.

C 2 (Fig. 4) ve C 4 (Fig. 5) sarnıçları ortak mimari özelliklere sahiptirler. Her ikisinin de rezervuar bölümleri şişe tipli değil, daha çok "hemisfer formlu” (Kürkçü 2014, 319), dikdörtgene yakın bir plana sahip, köşeleri yuvarlatılmış sarnıçlar olduğu, orta ölçekli moloz taşlarla örülü ve iyi durumda korunagelmiş pembemsi renkli hidrolik sıvayla kaplı duvarların ise içerilerine inşa edildikleri yapıların zemin seviyelerinin hemen altında, üzerlerini kapamak amacıyla yerleştirilen blokların dizilimini kolaylaştırmak için hafifçe daraldıkları gözlemlenmektedir. 


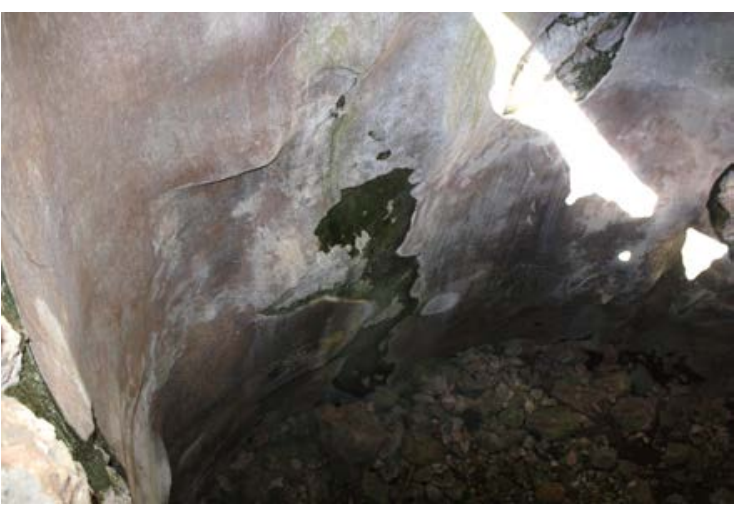

Fig. 4. Ariassos C 2 Sarnıcı

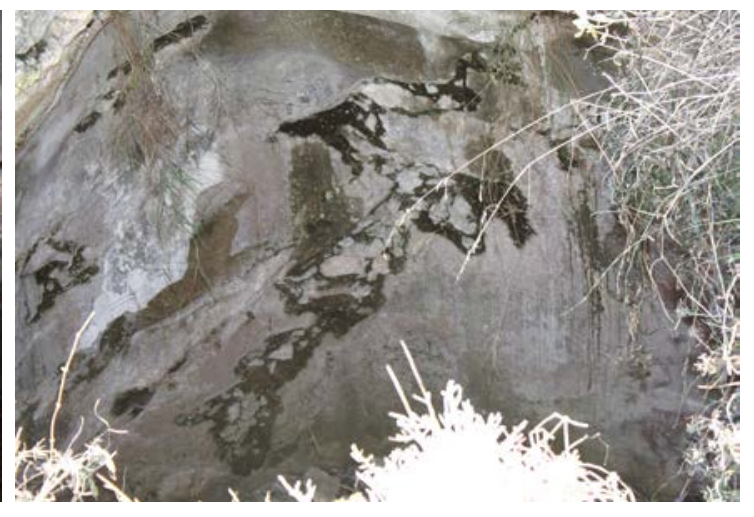

Fig. 5. Ariassos C 4 Sarnıcı

Daha iyi durumdaki C 4 (Kürkçü 2014, 322) sarnıcının üzerini örten dikdörtgen bloklardan iki tanesinin uzun kenarlarından biri üzerine, yan yana geldiklerinde çapı $0,49 \mathrm{~m}$ daire oluşturan yarım daire şeklinde açıklıkların yontulduğu görülür. Uzunluğu $5,14 \mathrm{~m}$ genişliği $2,82 \mathrm{~m}$ 'dir. Zemini kaplayan toprak yığınından itibaren yüksekliği 5,05 m olup yaklaşık $73 \mathrm{~m}^{3}$ kapasiteye sahiptir. Kentin Hellenistik Dönem'ine ait bir yapı içerisinde bulunması, modeli, çatı sistemi ve duvarlarda kullanılan sıva gibi mimari özellikleri göz önüne alındığında aynı dönem içerisine, Hellenistik Dönem'e tarihlenmesi uygundur.

C 5 (Fig. 6) sarnıcının rezervuar bölümü büyük ölçüde toprakla kaplıdır. İncelenebilen bölümü C 2 ve $C 4$ sarnıçlarına benzer mimari özelliklere sahip olmakla birlikte duvarların üst kısımlarının hatları nedeniyle "çan formlu sarnıç" olarak sınıflandırılmalıdır.

\section{Kremna}

Kremna kenti Burdur ili Bucak ilçesinin Çamlık köyüne kuş uçuşu 1200 m mesafede, Aksu vadisine hakim, 1241 m yükseklikte bir tepe üzerine kurulmuştur. Bulunduğu alan doğuya doğru daralan, güneye eğimli üçgen formda, kuzey, doğu ve güneyde sarp yamaçlar üzerinde yükselen ve kent savunması için büyük kolaylıklar sağlayan bir arazidir.

Kalıntıların Kremna'ya ait olduğunu ilk kez, kenti 1833 yılında bölgede araştırmalar yapan F. V. J. Arundell dile getirmiştir. Bu

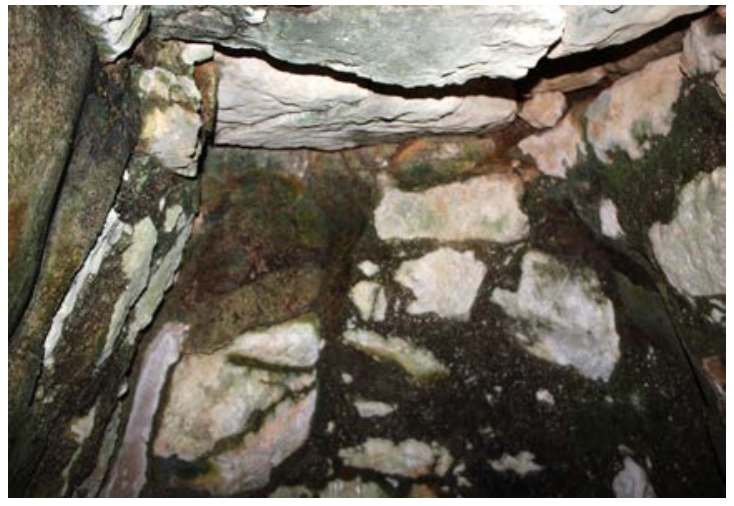

Fig. 6. Ariassos C 5 Sarnıcı dönemde yaptığg seyahati içeren notları yayınladığı iki ciltlik kitabının ilk bölümünde kentin basit bir planına da yer vererek “...eğer Kremna'nın başka bir yerde olduğunu düşünmemizi gerektirecek daha iyi nedenlerimiz yoksa burası olmalıdı"” $(1834,330)$ diyerek kalıntıların bu kente ait olduğunun kabul edilmesi gerektiğini belirtir.

W. H. Waddington $(1853,99), 1850$ yılında Anadolu'da gerçekleştirdiği dokuz aylık seyahati sonrasında yayınladığı eserindeki Kremna hakkındaki yorumu içerisinde kendisinden önce Kieppert'in de bölgede çalışmalar yaptığını dile getirmektedir: “... eski Pisidia kenti Kremna’ya ait dikkat çekici kalıntıların yamacında kurulu küçük Girme köyü... Bu kentin gerçek konumunu bir harita üzerinde ilk kez Kieppert belirlemiştir”. 


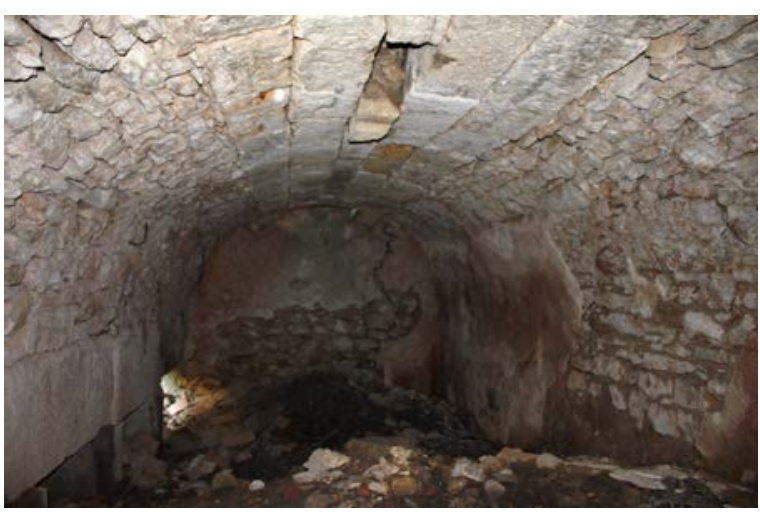

Fig. 7. Kremna Kamu Sarnıçları

Kent adının kesinlik kazanmasını sağlayan, Colonia Iul. Aug. Cremnensium tarafindan diktirilen anıttaki yazıt ise, 1874 y1lında Kremna'ya gelen G. Hirschfeld (1874, 306) tarafından bulunmuş ve yine aynı yıl Küçük Asya'nın güneybatısında yapılan seyahatin ön raporunda yayınlanmıştır.

C. Lanckoronski'nin Pamphylia ve Pisidia kentleri üzerine yazdığı ve günümüzde de önemini koruyan eserinin II. cildinde (Lanckoronski 1893, 168-181), içerisinde kent planı ve bazı çizimlerle bu çalışmada da incelenen bir sarnıcın bulunduğu Kremna'ya ayrılmış bir bölüm yer almaktadır.

Bu tarihten sonra kent çeşitli aralıklarla birçok araştırmacının dikkatini çekse de ilk ve tek kazının başlaması 1970 yılını bulur. J. İnan $(1972,51)$ bu kazıların amacını, antika soygunculuğuna karşı Eski Eserler ve Müzeler Genel Müdürlüğü’nün kenti sahiplenmesi, kaçak kazılar sonucu elde edilip sonrasında Burdur Müzesi'ne satılan 9 adet heykelin eksik parçalarının bulunması ve Q yapıs1 olarak adlandırılan kalıntıların gün 1şığına kavuşturularak plan ve kesitlerinin hazırlanması ve buna bağlı olarak yapının niteliğinin ortaya çıkarılması olarak ifade eder.

S. Mitchell (1986, 168-169), Kremna'da 1985 yılında başladığ 1 araştırmalarda kentin hidrografisine önem vermiş, çalışmalar "özenle işlenmiş su depolama yeri ve sistemi” ile nymphaeum arkasındaki sarnıçlar ve su sisteminin diğer yönleri üzerinde yoğunlaşmıştır. Araştırmacı 1986 yılında yayınladığı raporunda yerleşimin kuzeybatısındaki evlerin "merkezi su dağıtım yeri”ne (Mitchell 1987, 259) uzak olması sebebiyle bu kesimde çok sayıda su sarnıcı bulunduğunu belirtir. 1987 yılı araştırmalarını içeren yayınında (Waelkens 1987, 55) söz konusu merkezi su dağıtım yerinin kamu sarnıçları (Fig. 7) olduğu anlaşılmaktadır. Micthell'in raporlarında genellikle avluda ya da evlerin içerisinde tahkim edilen, özel kullanıma yönelik, mütevazi kapasitelere sahip küçük sarnıçlara yer verilmemiştir.

Mitchell'in ekibinden Kremna suyolu ve su sistemi konusunu inceleyen E. Owens (1991, 43-46) araştırmalarının sonuçlarını sunduğu makalesinde kentin doğal bir kaynaktan yoksun olduğunu, arazinin jeolojik yapısının su tutmaya imkan tanımadığını ve yerleşim içerisinde, yalnızca kent merkezine doğru tahkim edilen ikamet bölgesinde iki adet, konutlara ait kuyu tespit edildiğini dile getirir. Çalışma içerisinde özel kullanım amaçlı sarnıçlar üzerine herhangi bir detay ya da deskriptif bilgi verilmemekte bunun yerine "hemen her evin avlusunda bu alanı çevreleyen çatılardan toplanan yağmur sularınin beslediği ve genellikle antikçağın en yaygın modeli olan şişe tipli bir sarnıç bulunduğu" şeklinde klasik ve genel bir tanımlama yer almaktadır. Owens bunlarla birlikte birisi avlu içerisinde, yer altına inşa edilmiş, üzeri kireçtaşından plakalarla örtülü sade bir sarnıçla, daha büyük ölçülerde, ortasında üzerini örten kireçtaşından plakaları desteklemeye yönelik bir dikme

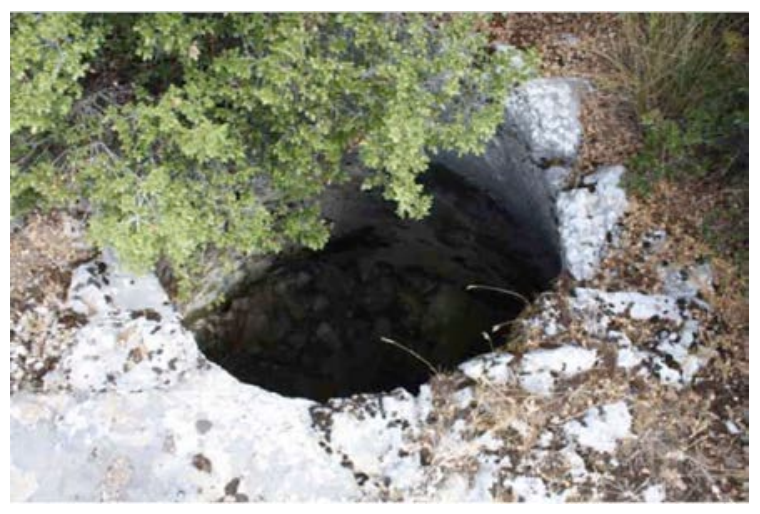

Fig. 8. Keritai Sarnıcı, (H. Metin 2014) 
bulunan iki adet dörtgen planlı su depolama yapısından bahseder.

H. Metin (2014, 7), Kremna ve Çevresi Yüzey Araştırması Projesi sürecinde kent teritoryumunun kuzeyindeki küçük yerleşimler ve askeri nitelikli yapıların tespitini amaçlayan çalışmalarında Keritai'de tespit ettikleri kuyuların Kremna örnekleriyle birebir benzer olduğunu belirtir. Söz konusu hidrolik yapının fotoğrafı (Fig. 8) (Metin 2014, 24, Res. 23) incelendiğinde bunun bir "kuyu" değil, ağız kısmı büyük ölçekli, kısmen traşlanıp biçimlendirilmiş taşlarla dairesel olarak inşa edilmiş, aşağılara doğru düzenli olarak genişleyen, dip kısmı moloz ve toprakla kaplı bir sarnıç olduğu görülür.

\section{Sarnıçlar}

Kremna'da gözlemlenen iki farklı sarnıçtan küçük olan1 (Kürkçü 2014, 326-327) (N 37²9' 55.1” E 030 41'04.5” yükseklik $1251 \mathrm{~m}$, hassasiyet $4 \mathrm{~m}$ ) silindirik bir forma sahip olup duvarlarında hidrolik sıva bulunmamaktadır. $0,76 \mathrm{~m}$ çapında, $3,44 \mathrm{~m}$ derinliğindeki yapının içerisinde biriktirilen suları korumak ve olası kazaları önlemek amaciyla zeminde, ağzının etrafında düzgün kesilmiş blok taşların dizilmesiyle dairesel bir strüktür oluşturulmuş ve bunun da üzerine, uzunluğu $1,16 \mathrm{~m}$, genişliği $1,13 \mathrm{~m}$ ve yüksekliği $0,26 \mathrm{~m}$ (zemindeki bloklarla yüksekliği toplam $0,42 \mathrm{~m}$ ) ölçülen dörtgen formlu, sade ve basit, monolitik bir kuyu bileziği (puteal) yerleştirilmiştir (Fig. 9). Bloğun yüzeyine ortalanan açıklık içinden su çekilmesine imkan sağlarken kuzeydoğu köşesinin altında bulunan delik burada sonlanan bir boru ile beslendiğini gösterir.

Termessos'ta söz konusu yapıya benzer mimari özelliklere sahip 2 adet (Kürkçü 2014, 324) (D 41, D 49) sarnıç tespit edilmiştir (Fig. 10).

Kremna'da tetkik edilen, kenar uzunlukları yaklaşı1 $4 \mathrm{~m}$ olarak hesaplanan (Lanckoronski 1893, 174, Lanckoroski ve ekibi bu sarnıç ölçülerini $5 \mathrm{~m}$ uzunluk ve $3 \mathrm{~m}$ genişlik olarak vermektedir. Bu rakamlar büyük olasılıkla sarnıcın dışından alınmış olmalıdır. 4 m olarak sunduğumuz ölçüler ise, sarnıcın rezervuar bölümüne ait olup iç

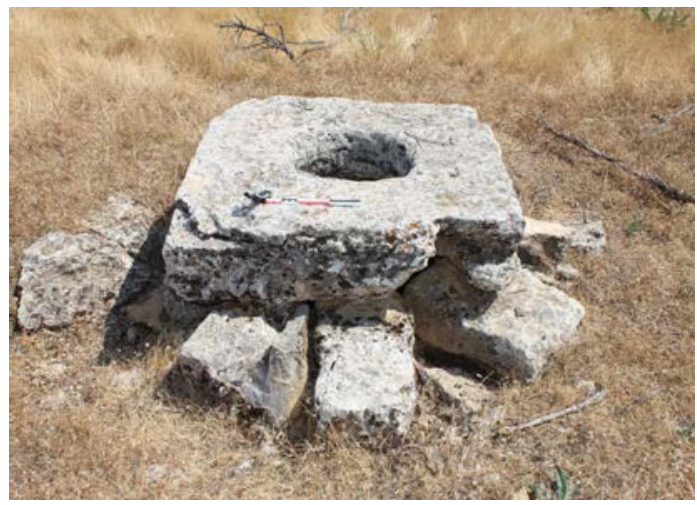

Fig. 9. Kremna, Kuyu Bileziği

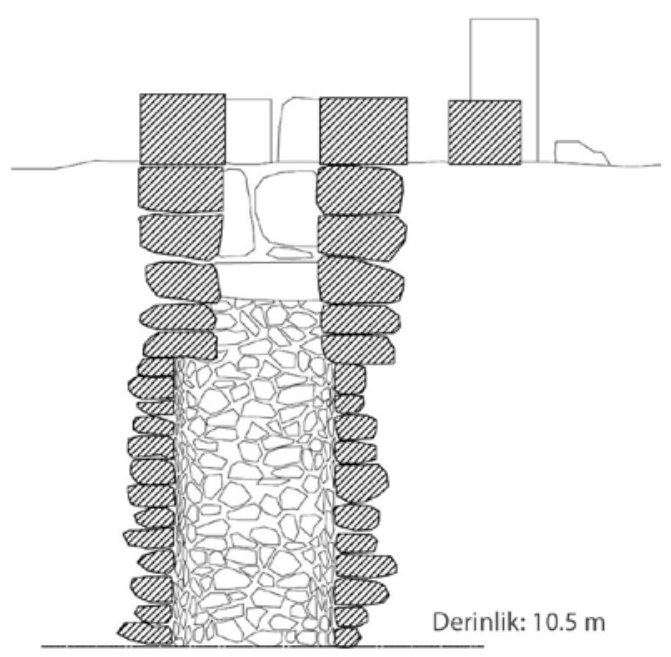

Fig. 10. Termessos D 49 Sarnicl (Y. GOUBIN, 2010)

kısmından hesaplanmıştır) kare planlı ikinci sarnıç kentteki kamu sarnıçlarının kuzeybatısında yer alır. Bu su depolama yapısı çatı sistemiyle (Fig. 11) dikkat çeker.

İçerisinde, orta alanda, aralarına harç konularak üst üste dizili dikdörtgen bloklardan oluşan bir dikme bulunmaktadır. Bu sayede sarnıcın güney duvarından kuzey duvarına aynı aks üzerinde kesintisiz devam edercesine iki adet dikdörtgen blok yerleştirilebilmiştir. İmpost üzerinde yükselen kemerlerin yerini burada dikme ve duvar üzerinde sabitlenen düz blokların aldığ1 görülür. Bu bloklar üzeri kaplanacak alanı iki eşit parçaya bölerek örtmede kolaylık sağlamaktadır. Doğu-batı yönünde yerleştirilen düzgün plakalar bir kenarı sarnıcın duvarına 


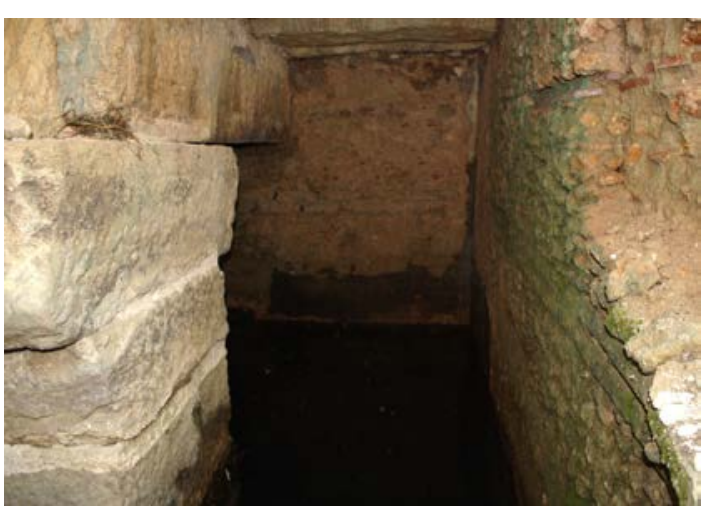

Fig. 11. Kremna, Dörtgen Sarnıç, Dikme, Kiriş ve Duvardaki Hasarlı Bölüm

diğeri ise bu blokların üzerine gelecek şekilde dizilerek rezervuar için çatı işlevi görürken aynı zamanda sarnıcın içerisinde yer aldığı mekanın zemini oluştururlar. Sarnıcı örten plakaların hemen kuzeybatısında, yaklaşık 2 m çapında, kesme taşlardan örülü dairesel bir strüktür bulunmaktadır (Fig. 12). Lanckoronski (1893, 174-175) söz konusu rezervuarın özel bir konuta ait olabileceğini, araştırma sürecinde günlük su ihtiyaçlarını buradan karşıladıklarını ve içerisine girmek için dairesel strüktürü kullandıklarını ifade eder.

Sarnıcın içerisinde hasara uğrayan bir bölümde duvarların orta ölçülerde (ca. $20 \mathrm{~cm}$.) moloz taşlar, harç ve düz bir hat üzerinde dizili pişmiş tuğlalarla arka arkaya iki sıra olarak örüldüğü görülür.

Anadolu'da araştırmalara konu olanlar içerisinde dikdörtgen planlı olup çatı sistemi Kremna örneğine benzer mimari özelliklere sahip herhangi bir sarnıca rastlanmaz. Bununla birlikte Bergama akropolisinde yangınlarla (Fahlbusch 2012, 43) mücadele etmek amacıyla inşa edilen dairesel formlu büyük sarnıcın içerisinde yuvarlak bir sütun bulunduğu görülür (Fig. 13). Rezervuarın örtülmesi sarnıç duvarından ortadaki bu sütuna birbirlerine dik açıyla yerleştirilen dört adet kiriş ve üzerlerine dizilen plakalarla sağlanmıştır (Brinker 1990, bk. Fig. 30). Fahlsbuch'a (2012, 43) göre, yangına müdahalede süratin önemi nedeniyle çatı için kullanılan kiriş ve plakalar, Kremna'da uygulanandan farklı olup, büyük bir olasılıkla ağaçtan yapılmışlardı.

\section{Değerlendirme}

Pisidia Bölgesi kentleri örneğinde görüldügü üzere, savunma stratejileri gereği dağlık coğrafyalarda, tepelik arazilerde tahkim edilen, içerilerinde ya da yakın çevrelerinde herhangi bir kaynaktan yoksun yerleşimlerde, insanların günlük yaşam ve kişisel hijyen için gereksinim duyduğu sular, yağmur sularının sarnıçlarda toplanmasıyla elde edilmiştir.

S. Mitchell (1998, 245), Ariassos ve Sia kentlerinin surlarını M.Ö. III. ve II. yüzyıllara Kremna kentini çevreleyen en erken surları, bilhassa Güney Kapısı'nı Geç Hellenistik Dönem'e tarihlendirmektedir (1989, 311).

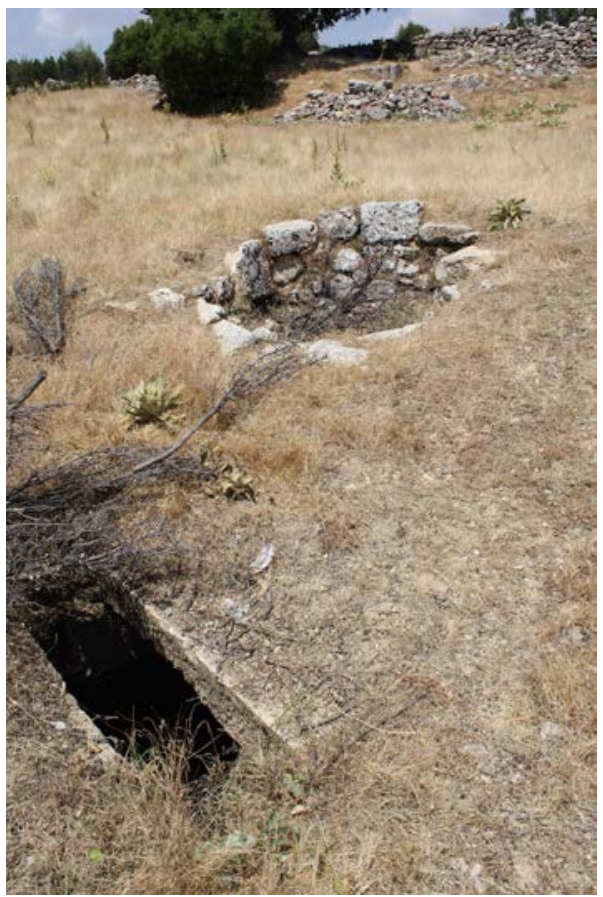

Fig. 12. Kremna, Dörtgen Sarnıç ve Dairesel Strüktür

Bunun yanında Kremna'da yer alan duvarları pembemsi renkli hidrolik sıvayla kaplı kamu sarnıçlarının üzerleri düzgün kesilmiş blok taşlar, moloz ve harçla inşa edilmiş tonoz çatılarla örtülmüştür. Bu mimari özellikleri göz önüne alındığında söz konusu yapıların kabaca Roma İmparatorluk Dönemi'nde inşa edildiği kabul edilebilir. Owens $(1991,56)$ da Kremna suyolu ve su sistemi üzerine yaptığı çalışmalarını yayınladığı makalesinde, kamu sarnıcının aquaeductus 
ile beslendiğini ve kentin su temin sisteminin Roma İmparatorluk Dönemi kentlerinin çoğunluğunda görüldüğünü belirtir.

Ariassos ve Kremna'da da aquaeductus ve kamu sarnıçları öncesinde kent halkı, Bergama (Fahlbusch 2014, 247-248) ve Termessos (Kürkçü 2014, 374) kentlerinde olduğu gibi, evlerde avlulara, iç mekanlara ve hatta kimi zaman konutlar arasındaki boş alanlara dahi sarnıçlar yaparak su kaybının önüne geçmeye çalışmış olmalıdır.

Mitchell’in "merkezi su dağıtım yeri” şeklindeki yorumu bir takım soruları da beraberinde getirir. Antik dönemde kent içindeki çeşmelere ve konutlara gelişmiş bir şebekeyle su dağıtımı konusunda Priene (Rhumscheid 2000, 104-105, ayrıca bk. Crouch D. P., Güngör T., Alkan A. 1997) ve Pompeii (Dessales 2008, 34) örnek gösterilebilir ancak Kremna'daki kamu sarnıçları için herhangi bir sistematik su dağıtımı söz konusu değildir. Owens da kent halkının sarnıçlar-

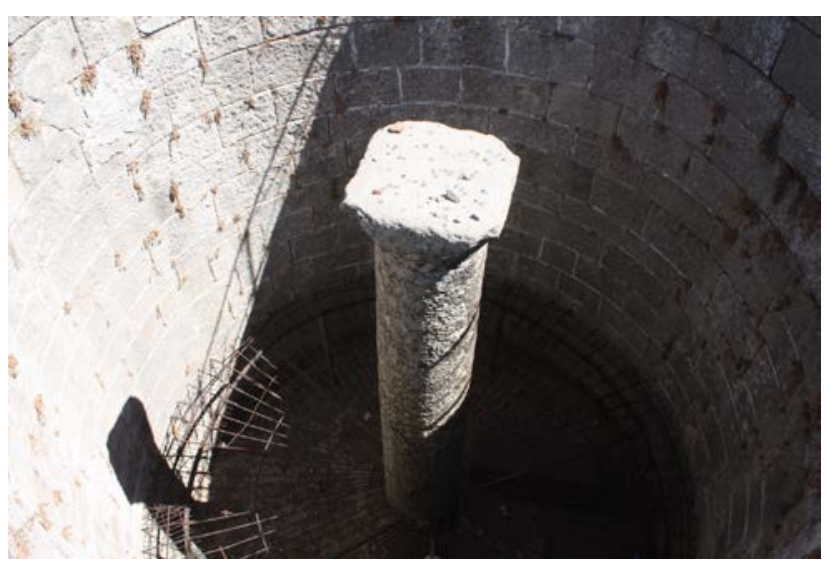

Fig. 13. Pergamon, Sütunlu Sarnıç daki suya direkt ulaşımının olmadığını belirtir (Owens 19991, 56). Söz konusu tarihe değin yapılan kazılarda Pompeii'de kamuya açık, bilhassa iki sokağın kesiştiği bölgelere yerleştirilmiş 49 adet çeşme gün 1şı̆̆ına çıkarılmıştır. Ayrıca kent içinde umuma açı ve evlerde dekor amaçlı çeşmeler ve su dağıtımı konusunda bk. H. Dessales 2013) örnek gösterilebilir. Bununla birlikte Kremna'daki kamu sarnıçları için herhangi bir sistematik su dağıtımı söz konusu değildir. Owens (1991, 56) da kent halkının sarnıçlardaki suya direkt ulaşımının olmadığını belirtir.

Ayrıca içerisinde su kaynağı bulunmayan Hellenistik Dönem kentlerinde, Mitchell'in bahsettiği üzere, konutların "merkez su dağıtımı yapısı" ya da çeşmelere olan uzaklığı, bu yapılar içerisinde şahsi kullanım amaçlı inşa edilen sarnıç sayısı üzerinde herhangi bir rol oynamaz. Roma Dönemi'nde kentlere suyolları inşa edip bol miktarlarda su temin edildikten sonra da evlerde bulunan sarnıçlar önemini korumuş, yapım ve kullanımlarına devam edilmiştir. Ayrıca herhangi bir kuşatma sırasında düşmanın suyollarına zarar verip kenti susuz bırakma riskini ortadan kaldırmak için temizlik ve bakımlarının düzenli olarak yapılması sağlanmış ve bu çalışmalar kentteki görevliler (astynomoi) tarafından belirli aralıklarla kontrol edilmiştir (Hellman 1999, 20).

Roma, M.Ö. IV. yüzyıl ve M.S. II. yüzyıllar arasında ele geçirdiği topraklarda, siyasi nüfusun imparatorluğun tamamına ulaşmasını sağlamak ve Roma halkının (Populus Romanus) saygınlığını ilan etmek amacıyla belli bir kent ve yerleşim modelini imparatorluk sınırları içerisinde kalan tüm bölgelere dayatmıştır (Gros 2005, 156).

Savaş ve çatışmaların yerini barış ve huzurun aldığ bu dönemde eyaletlerdeki şehircilik organizasyonları Pisidia Bölgesi'nde de hızlı bir şekilde yayılmıştır. İmparator'un gücünü ve Roma yaşam tarzını yansıtan kamu binaları içerisinde toplumun dinlenme, eğlenme ve huzurunu sağlamaya yönelik olanlardan su sistemlerine direkt bağlı aquaeductus, hamam, nymphaeum gibi yapılar birbiri ardına kentlerde inşa edilmeye başlanır.

M.Ö. II. ve I. yüzyıllardan itibaren Sagalassos'ta görülen gelişme hızı, heykel ve mimari süslemelerdeki yüksek kalite, denize kıyısı olmayan dağlık bir coğrafyada yerleşik Pisidia 
kentlerinin diğerlerinden geri kalmadığını gösterir (Mitchell 1987, 258). Bu gelişme sürecinde Sagalassos'un mimari açıdan diğer kentlere örnek olduğu muhakkaktır. Son araştırmalarda yerleşim bölgesi ve yakın çevresinde toplam 55 adet su kaynağı (M. Waelkens'in Antalya'daki 05.11.2014 tarihli konferansından alınmıştır [communication personel]) tespit edilen Sagalassos bu özelliğiyle diğer Pisidia kentleri için de model teşkil etmiş olmalıdır.

Mitchell (2001, 81), Roma kentlerinin M.S. II. yüzyılın ortalarından itibaren imparatorun prestijini yansıtmaya yönelik belli başı yapılarla donatılmış olması gerektiğini söyler. Bunlar hidrolik yapılar dışında dini amaçlı olanlar (kutsal alanlar, tapınak ve altar), politik amaçlı toplantı binaları (kent meclisi toplantıları için bouleuterion ve bazilika), halkın bir araya gelebileceği alanlar, kentsel uygarlık göstergesi durumundaki, sınırları ve formları aktivitesinin gerektirdiği şekilde biçimlendirilmiş kültür ve eğitime yönelik yapılar (gymnasion, odeion, tiyatro, kütüphane) ve farklı tip ve boyutlarda kenti süslemeye yönelik heykeller, zafer takları, anitsal yazitlar ve kahraman mezarlarıdır.

Sonuç olarak kentlerdeki tüm gelişmelere, hidrolik düzenlemelere rağmen Ariassos ve Kremna'da sınırlı kapasitelere sahip ev tipi sarnıçların halkın günlük su ihtiyacını karşılamadaki rollerinde herhangi bir değişiklik olmadığı, duvarları kaplayan sıva üzerinde zaman zaman yapılan onarımlar sonrasında kesintisiz hizmet vermeye devam ettikleri görülmektedir.

Ariassos ve Kremna'da diğer kentlerde de yaygın olarak kullanılan şişe tipli, çan ya da armut formlu klasik sarnıç modelleri dışında bu çalışmada ele alınan farklı modeller bölgeye has bir model olmadığını ortaya koyarken aynı zamanda, ileride Anadolu'da bulunan antikçağ sarnıçları üzerine oluşturulacak corpus için de önemli tipolojik katkılar sağlayacaktır.

\section{KAYNAKÇA}

Arundell F. V. J. (1834). Discoveries in Asia Minor. Vol. I. London 1834.

Berard V. (1892). “Inscriptions d'Asie Mineure”. BCH 16 (1892) 417-446.

Brinker W. (1990). Wasserspeicherung in Zisternen: Ein Beitrag des Wasserversorung früher Städte. Mitteilungen des Leichweiss-Instituts für Wasserbau der Technischen Univesität Braunschweig, 109 Braunschweig 1990.

Crouch D. P., Güngör T. \& Alkan A. (1997). "Priene and Pompeii: Cities in geologically active settings". Engineering Geology and the Enviroment, Proceedings of the International Symposium on Engineering Geology and the Environment, 3. Atina, 23-27 Haziran1997. Brookfield, A. A. Balkema (1997) 3107- 3112. Rotterdam.

Dessales H. (2008). “Des usages de l'eau aux évaluations démographiques: l'exemple de Pompéii”. Histoire urbaine 22 (2008) 25-39.

Dessales H. (2013). Le partage de l'eau: fontaines et distribution hydraulique dans l'habitat urbain de l'Italie romaine. Roma 2013.

Dorl-Klingenschmid, C. (2001). Prunkbrunnen in kleinasiatischen Städten. München 2001.

Fahlbusch H. (2014). “Antik Pergamon’da Su Temini, Anadolu'da Hellenistik Bir Başkent Pergamon”. (2014) 246-257. İstanbul.

Fahlbusch H. (2012). "The Big Cistern on the Acropolis of Pergamum - A Reservoir For the Storage of Water to Fight Against Fire”, IWA WWTAC 2012, $3^{\text {rd }}$ IWA (International Water Association) Specialized Conference on Water and Wastewater Tecnologies in Ancient Civilizations (2012) 43-48. İstanbul.

Gemma C. J. J. (2000). “Urban water transport and distribution”. Ed. Ö. Wikander. Handbook of Ancient Water Technology (2000) 103-125. Boston.

Gros P. (2005). "La ville comme symbole, le modèle central et ses limites". Şurada: Histoire de la Civilisation Romaine (2005) 205-232. Paris. 
Hellmann M. C. (1999). Choix d'inscriptions architecturales grecques, traduites et commentées. Lyon 1999.

Hirschfeld G. (1874). Vorläufiger Bericht über eine Reise im südwestlichen Kleinasien. U.K. 1874.

İnan J. (1970). “Kremna Kazısı Raporu”. Türk Arkeoloji Dergisi XIX/2 (1970) 51-97.

Lanckoronski C. (1893). Les villes de la Pamphylie et de la Pisidie. La Pisidie, 2. Paris 1893.

Kürkçü M. (2014). L'urbanisme et les aménagements hydrauliques de Termessos. Yayınlanmamış Doktora Tezi. Université de Paris-Sorbonne 2014.

Metin H. (2014). "Kremna Antik Kenti Kuzey Yayılımı Hakkında İlk Gözlemler”. Mehmet Akif Ersoy Üniversitesi, Sosyal Bilimler Enstitüsü Dergisi 6/11 (2014) 1-27.

Mitchell S. (2001). "Anatolia: land, men, and gods in Asia Minor”. The Celts in Anatolia and the impact of Roman rule, I. Oxford 2001.

Mitchell S. (1998). “The Pisidian Survey in Ancient Anatolia”. Ed. R. Metthews. Ancient Anatolia (1998) 237-253. Oxford.

Mitchell S. (1990a). “Archaeology in Asia Minor 1985-1989”. Archaeological Reports 36 (1990) 83-131.

Mitchell S. (1990b). "1988 Yılı Ariassos Yüzey araştırması”. AST VII (1990) 147-152.

Mitchell S. (1988). “The Siege of Cremna”. Eds. D. H. French \& C. S. Lightfoot. The Eastern Frontier of the Roman Empire I (1988) 321-328. Ankara.

Mitchell S. (1987). "Cremna Araştırmaları”. AST V/I (1987) 257-263.

Mitchell S. (1986). "Cremna ve Sagalassus Çalışması 1985”. AST IV (1986) 167-170.

Mitchell S. \& Owens E. \& Waelkens M. (1989). “Ariassos and Sagalassos 1988”. AS 39 (1989) 61-77.

Mitchell S. \& Waelkens M. (1988). “Cremna and Sagalassus 1987”. AS 38 (1988) 53-65.

Owens E. J. (2006). "The Aqueduct of Ariassos and the Development of the Roman City". Ed. G. Wiplinger. Cura Aquarum in Ephesus, Vol. 1 (Bulletin Antieke Beschaving. Suppl.12/Österreichisches Archäologisches Institut. Sonderschriften 42), (2006) 151-157. Peeters, Leuven - Paris - Dudley.

Owens E. J. (1991). "The Kremna Aqueduct and Water Supply in Roman Cities". Greece and Rome (Second Series), 38 (1991) 41-58.

Rhumscheid F. (2000). Küçükasya'nın Pompeisi Priene Rehberi. İstanbul 2000.

Waddington W. H. (1853). Voyage en Asie-Mineure au point de vue numismatique. Paris 1853. 